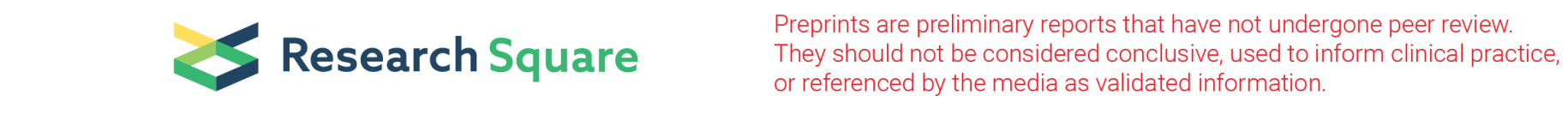

\title{
Predictors of wealth-related inequality in institutional delivery: a decomposition analysis using Nepal Multiple Indicator Cluster Survey (MICS) 2019
}

Umesh Prasad Bhusal ( $\sim$ umbhusal2020@gmail.com )

The University of Melbourne

\section{Research}

Keywords: Institutional delivery, Inequality, Concentration curve, Concentration index, Decomposition, Nepal, MICS

Posted Date: May 21st, 2021

DOI: https://doi.org/10.21203/rs.3.rs-539128/v1

License: (c) (i) This work is licensed under a Creative Commons Attribution 4.0 International License. Read Full License

Version of Record: A version of this preprint was published at BMC Public Health on December 1st, 2021. See the published version at https://doi.org/10.1186/s12889-021-12287-2. 


\section{Abstract \\ Background}

Inequality in maternal healthcare use is a major concern for low-and middle-income countries (LMICs). Maternal health indicators at the national level have markedly improved in the last couple of decades in Nepal. However, the progress is not uniform across different population sub-groups. This study aims to identify the determinants of institutional delivery, measure the wealth-related inequality, and examine the key components that explain the inequality.

\section{Methods}

Most recent nationally representative Multiple Indicator Cluster Survey (MICS) 2019 was used to extract data about married women (15-49 years) with a live birth within two years preceding the survey. Logistic regression models were employed to assess the association of independent variables with the institutional delivery. The concentration curves (CC) and concentration indexe (CIX) were used to analyze the inequality in institutional delivery. Wealth index scores were used as a socio-economic variable to rank households. Decomposition was performed to identify the determinants that explain socioeconomic inequality.

\section{Results}

The socio-economic status of households to which women belong was a significant predictor of institutional delivery, along with age, parity, four or more ANC visits, education status of women, area of residence, sex of household head, religious belief, and province. The concentration curve was below the line of equality and the relative concentration index (CIX) was $0.097(p<0.001)$, meaning the institutional delivery was disproportionately higher among women from wealthy groups. The decomposition analysis showed the following variables as the most significant contributor to the inequality: wealth status of women (53.2\%), education of women (17\%), residence (8.64 \%) and ANC visit (6.84 \%).

\section{Conclusions}

The pro-poor strategies are urgent to reduce the existing inequality between wealthy and poorer women. The strategies should focus on raising the education level of women especially from the rural and relatively backward province (Province 2). Increasing antenatal care (ANC) coverage through out-reach campaigns is likely to increase facility-based delivery and decrease inequality. Monitoring of healthcare indicators at different sub-population level (for example wealth, residence, province) is key to ensure equitable improvement in health status and achieve universal health coverage (UHC).

\section{Background}

Maternal health is a priority public health issue, well reflected in global development agendas. Reducing preventable maternal deaths was one of the key targets of millennium development goals (MDGs). It continues to be a target of sustainable development goals (SDGs). As per a global estimation done in 2017, maternal mortality ratio (MMR) was 211 per 100,000 live births (1). By 2030, the target of SDGs is to reduce it to less than 70 per 100,000 live births (2). Despite about a 38 percent reduction in global MMR since 2000, high maternal deaths is still a concern, particularly in low-and middle-income countries (LMICs), signalling the inequality in progress towards maternal health (1). MMR is 40 times higher in the low-income countries compared to that of Europe and 60 times higher than that of Australia and New Zealand.(1) South Asia accounts for nearly one in every five global maternal deaths (1). Low access to and utilization of health services during pregnancy and childbirth such as antenatal care (ANC), institutional delivery and skilled birth attendants (SBAs) are key factors responsible for a higher number of maternal deaths in this region (3). These deaths, to a larger extent, results 
from complications during delivery such as haemorrhage, sepsis, unsafe abortion, obstructed labour, and hypertensive disorders that could be prevented by switching from home to institutional delivery $(1,3-6)$. The skilled attendance at delivery in a hygienic environment and timely access to emergency care abate the risk of mortality or serious complications for both mother and newborn (7).

Equity in access to and utilization of health care services has received increased attention lately. It is one of the health system goals highlighted in the health system framework proposed by World Health Organization (WHO) in $2007(8,9)$, and a crucial element of universal health coverage (UHC) embodied in SDGs $(2,10)$. However, inequality in the distribution of access to and utilization of maternal health services both between and within countries continues to be a major concern for $\operatorname{LMICs}(7,11,12)$. Studies from different countries have shown that maternal health service utilization is disproportionately higher among women from wealthier households compared to their poorer counterparts; those living in an urban area compared to rural counterparts; those with higher education compared to non-educated counterparts; those belonging to the accessible geographical areas compared to remote counterparts $(3,6,7,13-18)$. Different socio-economic and demographic factors interact with each other and aggravate the situation of inequality.

The maternal health indicators at the national level have markedly improved in the last couple of decades in Nepal. The percent of women aged 15-49 years delivered in health institutions has increased from 8 in 1996 to 57 in 2016 (19). Similarly, percent of women receiving more than four antenatal care (ANC) has increased from 14 in 2001 to 69 in 2016 (19). The maternal mortality ratio (MMR) has decreased from 539 maternal deaths per 100,000 live births to 239 between 1996 and 2016 (19). This progress is attributed to a mix of supply and demand-side financing strategies introduced by Government of Nepal (GoN) since the 1990s (20-24). Establishment of birthing centres (BCs) and basic/comprehensive emergency obstetric centres (BEOCs/CEOCs) in remote and rural areas; skilled birth attendant training to nursing staffs and doctors of BCs and EOCs; expansion of blood transfusion services; strengthening of the referral services are key examples of supply-side financing. Likewise, maternity incentive scheme introduced in 2005 (transport incentive to mothers who deliver in health facilities) and revised subsequently in 2006 (user fees removed in all facilities in 25 districts with low human development index), 2009 (nationwide user fee removed and renamed as Aama program), and 2012 (incentive for completing recommended four ANC visits followed by institutional delivery introduced in 2009 merged with Aama program) are examples of demand-side financing.

However, the progress in maternal health in Nepal is not uniform across population from different geography and socioeconomy. The evidence show that the investment made in maternal health disproportionately favours women belonging to: an urban area, educated group, wealthy households, privileged ethnic group (25). Despite the focus of GoN towards enhancing equitable distribution and utilization of health services through policies and sector strategies, progress in narrowing the socio-economic inequality was not uniform across seven provinces in Nepal as demonstrated by the further analyses of nationally representative household surveys conducted before $2016(4,20,24,26)$.

GoN is committed to UHC and SDGs to be achieved by 2030. Hence, measuring health service utilization from the equity perspective using the most recent survey data is essential to ensure fair progress across population sub-groups. It is also of paramount importance to analyse the determinants of inequality so that evidence-based policy intervention could be taken by the policymakers. There is a dearth of studies that examine the determinants of inequality in maternal health in Nepal. The objective of this paper is three-fold: (i) to analyze the determinants of institutional delivery in Nepal using the most recent nationally representative household survey; (ii) to measure the socio-economic inequality in the use of institutional delivery services; (iii) to identify the main components that explain socio-economic inequality in institutional delivery through decomposition analysis.

\section{Methods}

\section{Study design and setting}


This study analyzed the Multiple Indicator Cluster Survey (MICS) 2019 data set. The survey was conducted in Nepal by the Central Bureau of Statistics (CBS) in technical and financial support from UNICEF. MICS is a nationally representative crosssectional survey that aims to monitor the situation of women and children by capturing the information on health,

education, social protection, environment, domestic violence along with the exhaustive set of socio-economic, demographic and geographic characteristics at the individual and household level. The survey used multistage probability designs to establish a representative sample of households at the national and province level. Within each province, the urban and rural areas were defined as the main sampling strata. The sample of households was selected in the following stages: (i) within each stratum, a specified number of census enumeration areas (EAs) were selected systematically with probability proportional to size, (ii) the household listing was carried out within the selected EAs. In total, 25 households were selected in each sample EA through a systematic random sampling method. For this round of survey, a total of 512 EAs and 12,800 households were selected. Out of which; 12,655 households, 14, 805 women (15-49 years), and 5,501 men (15-49 years) were successfully interviewed. Details of the MICS design and methodology are described elsewhere (27).

\section{Study population}

This study used data from married women (15-49 years) with a live birth within the two years preceding the survey. A total of 1,936 women (unweighted count $=2,500$ ) were included in this study and data analysis was conducted for their most recent live birth.

\section{Study variables}

The outcome variable used in this study was institutional delivery. It was categorized as " 1 " if women delivered her baby at health facility (both public or private) and " 0 " if women delivered her baby at home. The independent or explanatory variables included in this study are: age of women at the time of survey, number of births (parity), education status of women, exposure to media, four or more ANC visits for the most recent live birth, education status of household head, sex of household head, religion, ethnicity, area (rural and urban), province and wealth index quintile.

Age of women was categorized into four groups (1: 15-19 years; 2: 20-29 years; 3: 30-39 years; 4: 40-49 years). Religion was broadly categorized as Hindu and non-Hindu. More than 100 castes recorded during the survey were re-classified into four caste/ethnic groups based on Population Monograph of Nepal 2014 (28) (1: Brahmin, Chhetri and Madhesi; 2: Janajati from mountain, hill, and terai (plain northeast belt) and Newer; 3: Dalits from mountain hill and terai and Muslims; 4: rest (Marwadi, Bangali etc) as others). Education status of women and household head was categorized into four groups (0: without formal education; 1: primary education (grade one to five); 2: secondary education (grade six to ten); 3: higher secondary education and above (grade 11, 12 and above). Exposure to media was classified based on whether women were exposed to at least one source of mass media (0: no exposure; 1: limited exposure where women either listen to radio or watch TV or read magazine/newspaper less than once in a week; 2: exposure where women either listen to radio or watch TV or read magazine/newspaper at least once in a week to almost every day). Wealth index is a composite indicator of wealth and is commonly used as a proxy measure of socio-economic status of a household. To construct the wealth index, principal components analysis was performed by using information on the ownership of consumer goods, dwelling characteristics, water and sanitation, and other assets and durables that are related to the household's wealth (27). Since the wealth index provides an ordinal interpretation, it was used as a ranking variable of households.

\section{Method of analysis}

\section{Descriptive and regression analyses}

The characteristics of the women included in this study were described by using frequency and percentage. Bivariate and multivariate logistic regression models were used to assess the association of independent variables with institutional delivery. STATA 16 for the statistical analysis was used. Complex survey design was declared by using svyset command to account for sampling weights, clustering and stratification in the sampling design. Variance Inflation Factors (VIFs) were 
used to examine multicollinearity among covariates before building regression models. All covariates had VIFs less than 3.5 (maximum: 3.37; minimum: 1.06; average: 1.82). Goodness of fit test accounting for survey design (29) was used to assess the robustness of multivariate logistic regression model. All analyses were weighted.

\section{Inequality measurement}

The concentration curve (CC) and concentration index (CIX) in their relative formulation (with no correction), were used to analyze the inequality in the use of health services (institutional delivery) across socio-economic characteristics of the population (women) (30). The CIX presented in this paper corresponds to the horizontal inequity since every woman in the study were assumed to have an equal need for institutional delivery. While producing CC, cumulative proportion of women ranked by wealth index score (poorest first) was plotted on the x-axis against the cumulative proportion of institutional delivery on the $y$-axis. The 45-degree inclination from the origin showed perfect equality. If the CC overlaps with the line of equality, use of institutional delivery is equal among women. However, if the CC subtends the line of equality below (above), then inequality in the use of institutional delivery exists and is biased towards women belonging to low (high) socioeconomic status. The further the $\mathrm{CC}$ subtends from the line of equality, the greater the degree of inequality.

To quantify the magnitude of wealth-related inequality, $\mathrm{CIX}$ was calculated. CIX is defined as twice the area between the line of equality and CC (30). The following are the advantages of using CIX as a measure of inequality index in healthcare: it takes socio-economic dimension of healthcare inequalities into account since the classification of individuals is according to the socio-economic status, instead of their health status; it captures the experience of the whole population and; it is sensitive towards the changes in population distribution across socio-economic groups (15). The CIX takes a value between -1 and +1 . When the institutional delivery is equally distributed across socio-economic groups, $\mathrm{CIX}$ takes the value of 0 . $\mathrm{A}$ positive value of $\mathrm{CIX}$ implies that the use of institutional delivery is concentrated among the higher socio-economic groups (pro-rich). Conversely, a negative value of CIX suggests that the use of institutional delivery is concentrated among the lower socio-economic groups (pro-poor).

The calculation of CIX was done by using "convenient covariance" formula described by O'Donnell et al. (30), as shown in Eq. 1 below.

$$
C I X=\frac{2}{\mu} \operatorname{cov}(h, r)
$$

Here $h$ is the health sector variable, $\mu$ is its mean, and $r=i / N$ is the fractional rank of individual $i$ in the living standards distribution, with $\mathrm{i}=1$ for the poorest and $\mathrm{i}=\mathrm{N}$ for the richest. The user-written STATA commands Lorenz (31) and conindex (32) were used to produce CC and measure CIX, respectively.

\section{Decomposition of $\mathrm{ClX}$}

The decomposition of the relative CIX was performed to calculate the portion of inequality that is due to the inequality in underlying determinants. The technique explained by Wagstaff et al. (33) and O'Donnell et al. (30) were followed for the analysis and interpretation of results. The contribution of individual determinant of institutional delivery to the overall wealth-related inequality is calculated as the product of sensitivity of institutional delivery with respect to the determinant (elasticity) and the degree of wealth-related inequality in that determinant (CIX of determinant). Part of the CIX not explanined by the determinants is presented as residual. ADePT (version 6) software platform for automated economic analysis developed by World Bank was used for required calculations. Since the institutional delivery is a binary outcome variable, the non-linear model was specified while conducting the analysis.

\section{Results}




\section{Descriptive summary}

Table 1 shows the descriptive statistics for socio-economic and demographic characteristics of women aged 15-49 years disaggregated by the place of delivery (home delivery versus institutional delivery). Most of the women in this study belonged to age group 20-29 years, had one child, did four or more ANC visits, had secondary education, exposed to mass media, belonged to urban residence, had male as a household head, were from upper ethnic group, and were Hindu. Similarly, most of the women had household head without formal education, belonged to Province 2, and were from the poorest wealth quintile. Women from younger age groups were more likely to deliver in institutions compared to older age groups. More women having one or two births delivered in institutions compared to women with three, four or more births. Similarly, women who had four or more ANC were less likely to deliver at home compared to their counterparts. Higher education of women, urban residence and exposure to mass media was positively associated with institutional delivery. Women belonging to households with female head had a higher chance of institutional delivery compared to those belonging to households with male head. More women belonging to upper caste and Hindu religion had institutional delivery compared to Dalit and non-Hindu women. The education status of household head was positively associated with the institutional delivery. Women belonging to Gandaki Province were more likely to deliver in institutions, followed by Bagmati Province, Sudurpaschim Province, Province 1, Lumbini Province, Karnali Province and Province 2. Likewise, women from the richest quintile were more likely to deliver in institutions, followed by richer, middle, poor and poorer quintile. Except for age of women, there was strong evidence of an association between socio-economic and demographic characteristics of women and place of delivery (demonstrated by p-value for chi-square test, Table 1).

Overall, out of 1,936 women about $78 \%$ delivered in health institution and $22 \%$ delivered in home. 
Table 1

Socio-economic and demographic characteristics of women by place of delivery $(N=1,936)$

\begin{tabular}{|c|c|c|c|c|c|}
\hline Variables & $\begin{array}{l}\text { Weighted } \\
\text { frequency }\end{array}$ & Percent & $\begin{array}{l}\text { Home } \\
\text { delivery (\%) }\end{array}$ & $\begin{array}{l}\text { Institutional } \\
\text { delivery (\%) }\end{array}$ & $\begin{array}{l}\text { p-value for Chi- } \\
\text { square test }\end{array}$ \\
\hline \multicolumn{6}{|l|}{ Age of women in years } \\
\hline $15-19$ years & 200 & 10 & 19.1 & 80.9 & 0.097 \\
\hline $20-29$ years & 1307 & 68 & 20.9 & 79.1 & \\
\hline 30-39 years & 386 & 20 & 25.0 & 75.0 & \\
\hline $40-49$ years & 43 & 2 & 32.0 & 68.0 & \\
\hline \multicolumn{6}{|l|}{ Parity } \\
\hline One & 843 & 44 & 10.7 & 89.3 & $<0.001$ \\
\hline Two & 640 & 33 & 20.4 & 79.6 & \\
\hline Three & 250 & 13 & 43.1 & 56.9 & \\
\hline Four or more & 204 & 11 & 45.9 & 54.1 & \\
\hline \multicolumn{6}{|l|}{ ANC visit } \\
\hline Less than four & 342 & 19 & 41.7 & 58.3 & $<0.001$ \\
\hline Four or more & 1507 & 81 & 13.7 & 86.3 & \\
\hline \multicolumn{6}{|l|}{ Education status of women } \\
\hline No formal education & 404 & 21 & 45.7 & 54.3 & $<0.001$ \\
\hline Primary education (Grade1-5) & 260 & 13 & 28.3 & 71.7 & \\
\hline $\begin{array}{l}\text { Secondary education (Grade 6- } \\
\text { 10) }\end{array}$ & 813 & 42 & 18.9 & 81.1 & \\
\hline $\begin{array}{l}\text { HSS and above (Grade 11/12 } \\
\text { and above) }\end{array}$ & 460 & 24 & 2.3 & 97.7 & \\
\hline \multicolumn{6}{|l|}{ Exposure to mass media } \\
\hline No exposure & 550 & 28 & 38.2 & 61.8 & $<0.001$ \\
\hline Limited exposure & 186 & 10 & 21.5 & 78.5 & \\
\hline Exposure & 1200 & 62 & 14.3 & 85.7 & \\
\hline \multicolumn{6}{|l|}{ Area of residence } \\
\hline Rural & 668 & 34 & 33.3 & 66.7 & $<0.001$ \\
\hline Urban & 1269 & 66 & 15.7 & 84.2 & \\
\hline \multicolumn{6}{|l|}{ Sex of the household head } \\
\hline Female & 418 & 22 & 16.6 & 83.3 & 0.005 \\
\hline Male & 1518 & 78 & 23.2 & 76.8 & \\
\hline
\end{tabular}

Abbreviation: HSS = higher secondary education 


\begin{tabular}{|c|c|c|c|c|c|}
\hline Variables & $\begin{array}{l}\text { Weighted } \\
\text { frequency }\end{array}$ & Percent & $\begin{array}{l}\text { Home } \\
\text { delivery (\%) }\end{array}$ & $\begin{array}{l}\text { Institutional } \\
\text { delivery (\%) }\end{array}$ & $\begin{array}{l}\text { p-value for Chi- } \\
\text { square test }\end{array}$ \\
\hline Brahmin, Chhetri and Madhesi & 822 & 42 & 21.0 & 79.0 & $<0.001$ \\
\hline $\begin{array}{l}\text { Janajati and Newar (Mountain } \\
\text { Hill and Terai) }\end{array}$ & 674 & 35 & 18.7 & 81.3 & \\
\hline $\begin{array}{l}\text { Dalit (Mountain Hill and Terai) } \\
\text { and Muslim }\end{array}$ & 405 & 21 & 29.7 & 70.3 & \\
\hline Others & 35 & 2 & 7.2 & 92.8 & \\
\hline \multicolumn{6}{|l|}{ Religion } \\
\hline non-Hindu & 309 & 16 & 28.7 & 71.3 & 0.005 \\
\hline Hindu & 1627 & 84 & 20.5 & 79.5 & \\
\hline \multicolumn{6}{|l|}{$\begin{array}{l}\text { Education status of household } \\
\text { head }\end{array}$} \\
\hline No formal education & 769 & 39.7 & 28.3 & 71.7 & $<0.001$ \\
\hline Primary education (Grade $1-5$ ) & 391 & 20.2 & 24.2 & 75.7 & \\
\hline $\begin{array}{l}\text { Secondary education (Grade 6- } \\
\text { 10) }\end{array}$ & 568 & 29.3 & 17.4 & 82.6 & \\
\hline $\begin{array}{l}\text { HSS or above (Grade 11/12 and } \\
\text { above) }\end{array}$ & 208 & 10.7 & 4.9 & 95.0 & \\
\hline \multicolumn{6}{|l|}{ Province } \\
\hline Province 1 & 304 & 15.7 & 20.8 & 79.2 & $<0.001$ \\
\hline Province 2 & 414 & 21.4 & 64.4 & 35.6 & \\
\hline Bagmati Province & 382 & 19.7 & 10.7 & 89.2 & \\
\hline Gandaki Province & 150 & 7.8 & 8.6 & 91.4 & \\
\hline Lumbini Province & 369 & 19.1 & 21.6 & 78.4 & \\
\hline Karnali Province & 131 & 6.8 & 37.1 & 62.9 & \\
\hline Sudurpaschim Province & 186 & 9.6 & 15.5 & 84.4 & \\
\hline \multicolumn{6}{|l|}{ Wealth index quintile } \\
\hline Poorest & 438 & 22.6 & 42.3 & 57.7 & $<0.001$ \\
\hline Poor & 408 & 21.1 & 26.1 & 73.9 & \\
\hline Middle & 384 & 19.8 & 19.2 & 80.8 & \\
\hline Richer & 383 & 19.8 & 12.1 & 87.9 & \\
\hline Richest & 324 & 16.7 & 3.1 & 96.9 & \\
\hline Total & 1,936 & & 22 & 78 & \\
\hline
\end{tabular}

Results from the regression model 
Table 2 presents the estimate and the corresponding 95\% confidence interval $(\mathrm{Cl})$ for the bivariate and multivariate regression models as unadjusted odds ratio $(\mathrm{OR})$ and adjusted $\mathrm{OR}$, respectively. Both the bivariate and multivariate analyses showed that women who have completed four or more ANC visits; attained higher education; from urban residence; belonging to Hindu religion; and from wealthier quintiles were more likely to deliver in health institution in comparison to their respective counterparts. Conversely, the lower odds of institutional delivery were found for multiparous women; those living in male-headed household; and women belonging to Province 2 in comparison to the respective reference groups. Some variables (exposure to mass media, ethnicity, education status of household head, belonging to Bagmati, Gandaki or Karnali Province) that showed statistically significant association with institutional delivery in bivariate analyses did not show such association in multivariate analysis. Likewise, few associations were apparent only in the multivariate models (age of women, belonging to Sudurpaschim Province).

Women in age group 30 to 39 years were about two times (adjusted OR $=2.39 ; 95 \% \mathrm{Cl}: 1.29-4.42$ ) more likely to deliver in health institution compared to those in age group 15 to 19 years. Similarly, women in age group 40 to 49 years were about two and a half times (adjusted $\mathrm{OR}=2.66 ; 95 \% \mathrm{Cl}$ : 1.04-6.78) more likely to deliver in health institution compared to those in age group 15 to 19 years. Women who had delivered two, three, and four or more children already were significantly less likely to deliver in health institution compared to those who had only one child ever born. Women who had received four or more antenatal care (ANC) visits were nearly two and a half times more likely to deliver in health institution (adjusted OR = 2.54; 95\% Cl: 1.84-3.50) compared to those with fewer ANC visits. Women with higher secondary education or above were nearly five times more likely to deliver in health institution (adjusted OR $=5.18 ; 95 \% \mathrm{Cl}: 2.39-11.23$ ) compared to those without formal education. Similarly, women residing in urban area had greater odds of delivering in health institution (adjusted $\mathrm{OR}=1.80 ; 95 \% \mathrm{Cl}: 1.29-2.52$ ) compared to those living in rural setting. However, women from male-headed households were less likely to deliver in health facility (adjusted OR $=0.68 ; 95 \% \mathrm{Cl}$ : 0.47-0.98) compared to female-headed households. Regarding religion, Hindu women were more likely to deliver in health institution (adjusted OR $=1.69 ; 95 \% \mathrm{Cl}$ : 1.16-2.46) compared to non-Hindu women. Similarly, women from Sudurpaschim Province were more likely to deliver in health institution (adjusted $\mathrm{OR}=2.13 ; 95 \% \mathrm{Cl}: 1.06-4.29$ ) compared to those from Province 1. However, women from Province 2 were less likely to deliver in health institution.

Women belonging to higher wealth index quintile had greater odds of delivering in health institution compared to poorest quintile. Women from second, middle, richer and richest wealth index quintile were more than two times, four times, fifth times and seventh times more likely to deliver in health institution compared to poorest wealth quintile (reference), respectively. 
Table 2

Determinants of institutional delivery in Nepal (MICS 2019), N =1,936

\begin{tabular}{|c|c|c|}
\hline \multirow[t]{2}{*}{ Variables } & \multicolumn{2}{|c|}{ Odds ratio (95\% Confidence Interval) } \\
\hline & Unadjusted OR & Adjusted OR \\
\hline \multicolumn{3}{|l|}{ Age of women } \\
\hline $15-19$ years & Ref. & Ref. \\
\hline $20-29$ years & $0.89(0.60-1.33)$ & $1.58(0.98-2.55)$ \\
\hline $30-39$ years & $0.71(0.46-1.09)$ & $2.39(1.29-4.42)^{\star \star}$ \\
\hline $40-49$ years & $0.50(0.25-1.01)$ & $2.66(1.04-6.78)^{\star}$ \\
\hline \multicolumn{3}{|l|}{ Parity } \\
\hline One & Ref. & Ref. \\
\hline Two & $0.47(0.35-0.63)^{\star \star \star}$ & $0.41(0.28-0.59)^{\star \star \star}$ \\
\hline Three & $0.16(0.11-0.22)^{\star \star \star}$ & $0.21(0.14-0.32)^{\star \star \star}$ \\
\hline Four or more & $0.14(0.10-0.21)^{\star \star \star}$ & 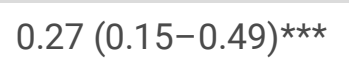 \\
\hline \multicolumn{3}{|l|}{ ANC visit } \\
\hline Less than four & Ref. & Ref. \\
\hline Four or more & $4.51(3.39-6.01)^{\star \star \star}$ & 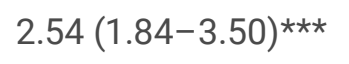 \\
\hline \multicolumn{3}{|l|}{ Education status of women } \\
\hline No formal education & Ref. & Ref. \\
\hline Primary education (Grade 1-5) & $2.13(1.54-2.95)^{\star \star \star}$ & $1.10(0.68-1.77)$ \\
\hline Secondary education Grade 6-10) & $3.61(2.68-4.86)^{\star \star \star}$ & $1.17(0.75-1.80)$ \\
\hline HSS and above (Grade $11 / 12$ or above) & 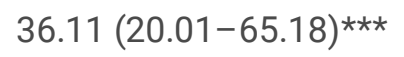 & $5.18(2.39-11.23)^{\star \star \star}$ \\
\hline \multicolumn{3}{|l|}{ Exposure to mass media } \\
\hline No exposure & Ref. & Ref. \\
\hline Limited exposure & $2.25(1.52-3.34)^{\star \star \star}$ & $1.19(0.74-1.90)$ \\
\hline Exposure & $3.71(2.86-4.82)^{\star \star \star}$ & $1.01(0.71-1.45)$ \\
\hline \multicolumn{3}{|l|}{ Area of residence } \\
\hline Rural & Ref. & Ref. \\
\hline Urban & $2.67(1.99-3.58)^{\star \star \star}$ & $1.80(1.29-2.52)^{\star \star \star}$ \\
\hline \multicolumn{3}{|l|}{ Sex of the household head } \\
\hline Female & Ref. & Ref. \\
\hline Male & $0.66(0.49-0.88)^{\star \star}$ & $0.68(0.47-0.98)^{*}$ \\
\hline
\end{tabular}

Abbreviation: MICS = Multiple Indicator Cluster Survey; OR = odds ratio; HSS = higher secondary education

${ }^{*} \mathrm{p}<0.05,{ }^{* *} \mathrm{p}<0.01, * \star * \mathrm{p}<0.001$ 


\begin{tabular}{|c|c|c|}
\hline Variables & \multicolumn{2}{|c|}{ Odds ratio (95\% Confidence Interval) } \\
\hline \multicolumn{3}{|l|}{ Ethnicity } \\
\hline Brahmin, Chhetri and Madhesi & Ref. & Ref. \\
\hline Janajati and Newar (Mountain Hill and Terai) & $1.16(0.84-1.60)$ & $1.14(0.77-1.68)$ \\
\hline Dalit (Mountain Hill and Terai) and Muslim & $0.63(0.46-0.86)^{\star \star}$ & $1.25(0.86-1.80)$ \\
\hline Others & $3.42(1.13-10.37)^{\star}$ & $2.32(0.72-7.44)$ \\
\hline \multicolumn{3}{|l|}{ Religion } \\
\hline non-Hindu & Ref. & Ref. \\
\hline Hindu & $1.57(1.15-2.15)^{\star \star}$ & $1.69(1.16-2.46)^{\star \star}$ \\
\hline \multicolumn{3}{|l|}{ Education status of household head } \\
\hline No formal education & Ref. & Ref. \\
\hline Primary education (Gr. 1-5) & $1.23(0.92-1.64)$ & $0.87(0.59-1.28)$ \\
\hline Secondary education Gr. 6-10) & $1.87(1.42-2.46)^{\star \star \star}$ & $0.98(0.71-1.35)$ \\
\hline HSS and above (Gr. 11/12 and above) & $7.58(4.11-13.96)^{\star \star \star}$ & $1.89(0.93-3.82)$ \\
\hline \multicolumn{3}{|l|}{ Province } \\
\hline Province 1 & Ref. & Ref. \\
\hline Province 2 & $0.48(0.29-0.79)^{\star \star}$ & $0.42(0.25-0.72)^{\star \star}$ \\
\hline Bagmati Province & $2.18(1.22-3.92)^{\star \star}$ & $1.29(0.69-2.41)$ \\
\hline Gandaki Province & $2.79(1.43-5.44)^{\star \star}$ & $1.35(0.64-2.83)$ \\
\hline Lumbini Province & $0.96(0.57-1.59)$ & $0.80(0.45-1.42)$ \\
\hline Karnali Province & $0.45(0.26-0.76)^{\star \star}$ & $1.05(0.53-2.06)$ \\
\hline Sudurpaschim Province & $1.43(0.78-2.60)$ & $2.13(1.06-4.29)^{*}$ \\
\hline \multicolumn{3}{|l|}{ Wealth index quintile } \\
\hline Poorest & Ref. & Ref. \\
\hline Second & $2.07(1.52-2.83)^{\star \star \star}$ & $2.63(1.68-4.12)^{\star \star \star}$ \\
\hline Middle & $3.07(2.09-4.50)^{\star \star \star}$ & $4.62(2.73-7.82)^{\star \star \star}$ \\
\hline Richer & $5.33(3.49-8.13)^{\star \star \star}$ & $5.39(2.99-9.69)^{\star \star \star}$ \\
\hline Richest & $22.55(10.45-48.64)^{\star \star \star}$ & $7.19(2.80-18.46)^{\star \star \star}$ \\
\hline \multicolumn{3}{|c|}{ Abbreviation: MICS = Multiple Indicator Cluster Survey; OR = odds ratio; HSS = higher secondary education } \\
\hline${ }^{*} \mathrm{p}<0.05,{ }^{* *} \mathrm{p}<0.01,{ }^{* \star *} \mathrm{p}<0.001$ & & \\
\hline
\end{tabular}

\section{Results from the measures of inequality}

Figure 1 depicts average institutional delivery over wealth index quintiles. Just under 60 percent of women in the poorest wealth quintile delivered in health institutions compared to about 95 percent in the richest counterpart. The graph demonstrates that institutional delivery increases monotonically in moving from women in the poorest wealth quintile to 
the richest wealth quintile. Figure 2 shows the inequality in institutional delivery by wealth status. Since the concentration curve is below the line of equality, the institutional delivery was disproportionately higher among women from wealthy groups. Table 3 presents value of relative CIX for institutional delivery. A positive estimated CIX in indicates that the institutional delivery was concentrated among the wealthier women in comparison to their poor counterparts.

Table 3

Relative and Wagstaff normalized concentration indexes

\begin{tabular}{|lcc|}
\hline Measure of inequality & Value & Standard error (p-value) \\
\hline Relative $\mathrm{CIX}$ & 0.097 & $0.008(<0.001)$ \\
\hline Abbreviation: $\mathrm{CIX}=$ concentration index & \\
\hline Note: Standard errors accounted for clustering at the level of primary sampling unit (PSU) \\
\hline
\end{tabular}

Table 4 presents the result of decomposition analysis of the relative CIX used to ascertain the contributions of different determinants towards wealth-related inequality in institutional delivery. The major contribution to the inequality was from the wealth status of household women belongs (53\%), followed by education (17.02\%), area of residence (8.64\%), and ANC visit $(6.84 \%)$ The residual contribution $(13.7 \% \%)$ represents the amount of wealth-related inequality not explained by the determinants used in the analysis.

Table 4

Decomposition of concentration index (CIX)

\begin{tabular}{|lllll|}
\hline Variables & Elasticity & CIX of determinant & Contribution to total CIX & Percent contribution \\
\hline Age & 0.0537 & 0.0113 & 0.0006 & 0.62 \\
\hline ANC visit & 0.1730 & 0.0383 & 0.007 & 6.84 \\
\hline Education (women) & 0.1467 & 0.1125 & 0.017 & 17.02 \\
\hline Residence & 0.1246 & 0.0672 & 0.008 & 8.64 \\
\hline Wealth & 0.1896 & 0.2722 & 0.052 & 53.20 \\
\hline Residual & & & 0.0133 & 13.70 \\
\hline Total & & 0.097 & \\
\hline Abbreviation: $\mathrm{CIX}=$ concentration index & & \\
\hline
\end{tabular}

\section{Discussion}

This study analyzed the determinants of institutional delivery in Nepal using the most recent MICS 2019. The odds of Nepalese women giving birth in health institutions with respect to their socio-economic and demographic characteristics was measured. Further, the wealth-related inequality in institutional delivery was calculated along with a decomposition analysis to find out the key determinants that explain the inequality. The study found that age of women, parity, four or more ANC visit, education status of women, area of residence, sex of household head, religious belief, province, and wealth index quintile were significant determinants for the institutional delivery. The institutional delivery was disproportionately higher among women belonging to wealthy households. The decomposition of the concentration index showed that the wealth-related inequality was explained mostly by household wealth, education status of women, urban residence, and ANC visits. 
The odds of institutional delivery increased with the increase in age of women. The women above age 30 years were more than two times more likely to have institutional delivery compared to that of age below 15-19 years. This finding corroborates previous study that analyzed first-order births in 34 countries of sub-Saharan Africa and found that older age at birth was associated with significantly higher odds of facility-based delivery (34). Finding from this study aligns well also with the study from Bangladesh (35). However, the non-significant association was obtained in analysis from Pakistan and Ethiopia $(3,36)$. Further research are needed to investigate this intercountry variance. The likelihood of institutional delivery decreased with an increase in parity. This result support finding from similar studies conducted in developing countries that have shown that experienced mothers were less likely to opt for facility-based delivery $(3,7)$. One possible explanation for the low uptake of institutional delivery among high parity women is that women with birth history may develop confidence from the knowledge and experience acquired from earlier pregnancies and therefore are less motivated to opt for services from health facilities (7). The odds of institutional delivery was twice in women who have completed four or more ANC visits. Positive association between the antenatal visits and facility-based delivery was found in previous studies conducted in Kenya, Ethiopia, Nepal, Bangladesh, Pakistan $(3,4,6,35,37)$. The counselling on birth preparedness received from health workers during the antenatal visits could be the reason.

The women with higher education were significantly more likely to deliver in health institution compared to women without formal education. Similar findings were obtained from studies conducted in other developing countries, establishing education as a significant determinant of facility-based delivery $(3,14,15,36,38,39)$. This association could be attributed to the fact that educated women are more likely to have a better understanding of risks associated with childbirth and benefits of using skilled healthcare compared to uneducated women. This evidence implies that inequality in institutional delivery could be reduced with appropriate intervention targeted to educate women. To reduce the barriers in uptake of maternal health services, GoN of Nepal has been implementing Birth Preparedness Package (BPP) through health workers and Female Community Health Volunteers (FCHVs) in the community since the early 2000s as part of the safe motherhood program (40). BPP educates pregnant women, their families, and communities to plan for normal pregnancy, delivery, and postnatal period and creates demand for healthcare through inter-personal communication using specially designed cards and flipcharts. So, more focused outreach education and awareness campaigns are key to further reduce the inequality in use of maternal healthcare services between educated and uneducated mothers.

The women from urban area were nearly two times more likely to opt for institutional delivery compared to the ones from rural counterparts. The findings from this study corroborate those of prior studies, where it was shown that urban residence of mother was associated with an increase in the use of institutional delivery $(3,15,17,36,41)$. In general, women from urban area have better access to healthcare system due to better transport, well-equipped hospitals and less distance between residence and health facility $(15,17)$. Studies based in rural settings of Nepal have identified access to birthing facilities, perception regarding the quality of healthcare, lack of transportation, poor infrastructure and equipment at birthing centres as key barriers to access facility-based delivery services (42-44).

Women from Province 2 were significantly less likely to deliver in health institutions compared to women from Province 1. Province 2 is terai (plain northeast belt) of Nepal and generally falls behind other provinces in terms of public health coverage indicators (20) and health infrastructure. As per the evidence from nationally representative surveys it had the lowest percentage of facilities providing normal vaginal delivery (45) and lowest mean general health service readiness score (46). It observed the lowest annual change in Human Development Index (HDI) since 1996 and had one of the third lowest HDI of 0.485 (national average $=0.522$ ) in $2011(47)$. Focused measures that address the unique socio-economic positioning are urgent to bring maternal health indicators of Province 2 at par with the national average.

Institutional delivery increased monotonically in moving from women in poorest wealth quintile to richest wealth quintile. Analysis of concentration curve and concentration index revealed a pro-rich inequity in institutional delivery. The result from this study is consistent with findings from similar studies where it was shown that better socio-economic condition of mothers was associated with an increase in the use of maternal healthcare services $(7,14-18,39,48,49)$. Women

Page $13 / 21$ 
belonging to higher socio-economic group have a better chance to visit health facility and when required, make payment for the expenses related to travel and medical care $(15,48)$. Various studies indicate the potential reasons for disproportionally lower coverage of maternal health services among women from lower socio-economic group: direct and indirect cost related to healthcare including travel expenses and opportunity cost; perceived quality of care in public facilities; perceived importance of seeking formal healthcare during pregnancy and childbirth. This indicates that the efforts of government since the 1990s to address barriers posed by Nepalese, mainly the poor households, through various supply and demandside financing are still insufficient. However, as observed in earlier analysis conducted using four rounds of Nepal Demographic and Health Survey (NDHS: 2001, 2006, 2011, 2016), the socio-economic inequality concerning institutional delivery between the socio-economic groups measured by relative CIX has, on average, narrowed over this period (20). The relative CIX obtained from these four rounds of NDHS were $0.56,0.48,0.35$ and 0.19 , respectively (20). The analysis presented in this paper using the data from MICS 2019 has shown that the relative CIX for institutional delivery has further narrowed down to 0.097 . So, the investment made by GoN looks working, but it should be more focused on benefiting the lower socio-economic group (in contrast to the current blanket approach with more emphasis on national targets), to further reduce the inequality gap. The decomposition analysis found that household wealth status contributes significantly towards the inequality in institutional delivery (53.2\%), followed by women's education (17.02\%.), urban residence (8.64\%) and ANC visit (6.84\%). This implies that the future policies and strategies need to be pro-poor, pro-rural and that needs to focus more on educating women and families for increased ANC uptake. The result of decomposition analysis presented in this paper is consistent with similar studies from developing countries $(15,17,18,50)$.

Few variables that did not demonstrate a significant association with institutional delivery in this study showed statistically significant association in studies conducted in other settings. Unlike Pulok et al. (7), Ketemaw et al. (36) this study found no statistically significant association between media exposure and institutional delivery. Similarly, unlike Atake (15), Pulok et al. (7) and Obiyan and Kumar (51), this study found no statistically significant association between education status of the household head (usually male/husband in Nepalese context) and institutional delivery. More studies might be required to ascertain these association.

\section{Strength of this study}

This study has used the most recent nationally representative household survey conducted in 2019. Rigorous statistical methods to calculate the odds of enrollment controlling for relevant socio-economic and demographic variables were employed. Further, this study offers the composite measure of inequality using standard techniques. The decomposition analysis was conducted to identify determinants that explain the inequality in the use of institutional delivery in Nepal.

\section{Limitation of this study}

First, the list of determinants of institutional delivery included in this study is not an exhaustive one. The potential determinants such as employment status of women, distance to the nearest institution with the birthing facility, cost (direct or indirect) associated with institutional delivery, understanding of the importance of safe delivery could not be included in this analysis due to the unavailability of such data in this round of MICS. Second, since this study is cross-sectional, it could not establish any causal relationship between the variables under study and institutional delivery. Notwithstanding, this study has elicited empirical evidence on socio-economic inequality and its predictors regarding institutional delivery which have policy relevance to countries with similar socio-economic context to Nepal.

\section{Conclusion}

Age of women, parity, four or more ANC visit, education status of women, area of residence, sex of household head, religious belief, province and household wealth were found to be important predictors of institutional delivery in Nepal. Institutional delivery was found to be disproportionately higher among women belonging to wealthy households. The decomposition of the concentration index showed that wealth-related inequality was explained mostly by socio-economic 
status of household, education status of women, residence, and ANC visit. The pro-poor strategies are urgent to further reduce the existing inequality between women belonging to different socio-economic groups. The strategies should focus on raising the education level of women especially from the rural and backward province (Province 2). Increasing antenatal care coverage through the outreach campaign is likely to increase facility-based delivery and reduce the gap between poor and wealthy women. Monitoring of healthcare indicators at different sub-population level (for example wealth, residence, education, province) is key to ensure equitable improvement in health status and achieve universal health coverage (UHC) by 2030 .

\section{Abbreviations}

\begin{tabular}{|ll|}
\hline ANC & Antenatal care \\
\hline BC & Birthing center \\
\hline BEOC & Basic emergency obstetric care \\
\hline BPP & Birth preparedness practice \\
\hline CBS & Central Bureau of Statistics \\
\hline CC & Concentration curve \\
\hline CEOC & Comprehensive emergency obstetric care \\
\hline CIX & Concentration index \\
\hline DHS & Demographic and health survey \\
\hline FCHV & Female community health volunteers \\
\hline GoN & Government of Nepal \\
\hline HDI & Human development index \\
\hline LMIC & Low-and middle-income country \\
\hline MDG & Millinnium development goal \\
\hline MICS & Multiple indicator cluster survey \\
\hline MMR & Maternal mortality rate \\
\hline OR & Odds ratio \\
\hline SBA & Skilled birth attendant \\
\hline SDG & Sustainable development goal \\
\hline UHC & Universal health coverage \\
\hline UNICEF & United Nations Children's Fund \\
\hline WHO & World Health Organization \\
\hline
\end{tabular}

\section{Declarations}

\section{Ethics approval and consent to participate}

This study is based on publicly available MICS datasets. The permission to access and use these datasets was obtained from Unicef/MICS website (http://mics.unicef.org/surveys), so no further ethical approval was necessary. The protocol for 
the survey was approved by the Central Bureau of Statistics (CBS) as per the Statistical Act (1958) in September 2018. Verbal consent was obtained from each respondent after a thorough introduction of the survey. All respondents were briefed about the voluntary nature of participation. Participants were assured that the information they share during the interview will be kept confidential and anonymous

\section{Consent for publication}

Not applicable

\section{Availability of data and materials}

Publicly available data were used that are accessible from the MICS website (https://mics.unicef.org/surveys) upon request.

\section{Competing interests}

The author declares that there are no conflicts of interest regarding the publication of this paper. The views and opinions expressed in this article are those of the author and do not necessarily reflect the official policy or position of the organization(s) the author is affiliated with.

\section{Funding}

This research received no specific grant from any funding agency in the public, commercial or not-for-profit sectors.

\section{Authors' contributions}

UPB conceptualized and designed the study, extracted data, conducted literature review, performed statistical analyses and interpretation of the result. UPB prepared and revised the manuscript and approved it for submission.

\section{Acknowledgements}

The author would like to acknowledge the Multiple Indicator Cluster Surveys (MICS) for their permission to access and use the dataset for this study.

\section{Authors' information}

UPB has a Master of Public Health with specialization in health economics and economic evaluation from The University of Melbourne, Australia. He is working in the sector of health and social protection based in Nepal since 2009. His research area and interest are health and social protection system in low-and middle-income countries; health equity analysis; health insurance and financing; maternal \& child health.

\section{References}

1. World Health Organization. Trends in maternal mortality 2000 to 2017: estimates by WHO, UNICEF, UNFPA, World Bank Group and the United Nations Population Division: executive summary [Internet]. 2019. Available from: https://apps.who.int/iris/handle/10665/327596

2. Nations U. THE 17 GOALS | Sustainable Development [Internet]. Department of Economic and Social Affairs. 2020 [cited 2021 Apr 25]. Available from: https://sdgs.un.org/goals

3. Rahman MA, Rahman MA, Rawal LB, Paudel M, Howlader MH, Khan B, et al. Factors influencing place of delivery: Evidence from three south-Asian countries. PLoS One [Internet]. 2021;16(4):e0250012. Available from: http://dx.doi.org/10.1371/journal.pone.0250012 
4. Devkota B, Maskey J, Pandey AR, Karki D, Godwin P, Gartoulla P, et al. Determinants of home delivery in Nepal - A disaggregated analysis of marginalised and non-marginalised women from the 2016 Nepal Demographic and Health Survey. Budhathoki SS, editor. PLoS One [Internet]. 2020 Jan 30 [cited 2021 Apr 25];15(1):e0228440. Available from: https://dx.plos.org/10.1371/journal.pone.0228440

5. Benova L, Macleod D, Radovich E, Lynch CA, Campbell OMR. Should i stay or should i go?: Consistency and switching of delivery locations among new mothers in 39 Sub-Saharan African and South/Southeast Asian countries. Health Policy Plan [Internet]. 2017 Nov 1 [cited 2021 Apr 25];32(9):1294-308. Available from: https://academic.oup.com/heapol/article/32/9/1294/4065273

6. Ketemaw A, Tareke M, Dellie E, Sitotaw G, Deressa Y, Tadesse G, et al. Factors associated with institutional delivery in Ethiopia: A cross sectional study. BMC Health Serv Res [Internet]. 2020 Mar 31 [cited 2021 Mar 10];20(1):266. Available from: https://bmchealthservres.biomedcentral.com/articles/10.1186/s12913-020-05096-7

7. Pulok MH, Sabah MNU, Uddin J, Enemark U. Progress in the utilization of antenatal and delivery care services in Bangladesh: Where does the equity gap lie? BMC Pregnancy Childbirth [Internet]. 2016;16(1). Available from: http://dx.doi.org/10.1186/s12884-016-0970-4

8. A new era for the WHO health system building blocks? | Health Systems Global [Internet]. [cited 2021 May 1]. Available from: https://healthsystemsglobal.org/news/a-new-era-for-the-who-health-system-building-blocks/

9. World Health Organization. Everybody business: strengthening health systems to improve health outcomes: WHO's framework for action. 2007.

10. Universal Health Coverage [Internet]. [cited 2021 Mar 1]. Available from: https://www.who.int/health-topics/universalhealth-coverage\#tab=tab_1

11. Barros AJ, Ronsmans C, Axelson H, Loaiza E, Bertoldi AD, Frana GV, et al. Equity in maternal, newborn, and child health interventions in Countdown to 2015: A retrospective review of survey data from 54 countries. Lancet [Internet]. 2012 [cited 2021 Apr 26];379(9822):1225-33. Available from: www.thelancet.com

12. Okoli C, Hajizadeh M, Rahman MM, Khanam R. Geographical and socioeconomic inequalities in the utilization of maternal healthcare services in Nigeria: 2003-2017. BMC Health Serv Res [Internet]. 2020 Sep 10 [cited 2021 Mar 10];20(1):849. Available from: https://bmchealthservres.biomedcentral.com/articles/10.1186/s12913-020-05700-w

13. Krishnamoorthy Y, Majella MG, Rajaa S. Equity in coverage of maternal and newborn care in India: Evidence from a nationally representative survey. Health Policy Plan [Internet]. 2020 Jun 1 [cited 2021 Mar 10];35(5):616-23. Available from: https://academic.oup.com/heapol/article/35/5/616/5814880

14. Rahman M, Haque SE, Mostofa MG, Tarivonda L, Shuaib M. Wealth inequality and utilization of reproductive health services in the Republic of Vanuatu: Insights from the multiple indicator cluster survey, 2007. Int J Equity Health. $2011 ; 10$.

15. Atake E. Socio-economic inequality in maternal health care utilization in Sub-Saharan Africa: Evidence from Togo. Int $J$ Health Plann Manage [Internet]. 2021 [cited 2021 Mar 10];36(2):288-301. Available from:

https://pubmed.ncbi.nlm.nih.gov/33000498/

16. Myint ANM, Liabsuetrakul T, Htay TT, Wai MM, Sundby J, Bjertness E. Inequity in the utilization of antenatal and delivery care in Yangon region, Myanmar: A cross-sectional study. Int J Equity Health [Internet]. 2018 May 22 [cited 2021 Mar 9];17(1):63. Available from: https://equityhealthj.biomedcentral.com/articles/10.1186/s12939-018-0778-0

17. Kim C, Saeed KMA, Salehi AS, Zeng W. An equity analysis of utilization of health services in Afghanistan using a national household survey. BMC Public Health [Internet]. 2016;16(1):1-11. Available from: http://dx.doi.org/10.1186/s12889-016-3894-z

18. Huda TM, Hayes A, Dibley MJ. Examining horizontal inequity and social determinants of inequality in facility delivery services in three South Asian countries. J Glob Health. 2018;8(1). 
19. Ministry of Health, Nepal; New ERA; and ICF. 2017. 2016 Nepal Demographic and Health Survey Key Findings. Kathmandu, Nepal: Ministry of Health Nepal.

20. Sapkota VP, Bhusal UP, Acharya K. Trends in national and subnational wealth related inequalities in use of maternal health care services in Nepal: an analysis using demographic and health surveys (2001-2016). BMC Public Health. 2021;21(1):1-14.

21. Ensor T, Bhatt H, Tiwari S. Incentivizing universal safe delivery in Nepal: 10 years of experience. Health Policy Plan. 2017;32(8):1185-92.

22. Murray SF, Hunter BM, Bisht R, Ensor T, Bick D. Effects of demand-side financing on utilisation, experiences and outcomes of maternity care in low- and middle-income countries: A systematic review. BMC Pregnancy Childbirth. 2014;14(1).

23. Bhatt $\mathrm{H}$, Tiwari S, Ensor T, Ghimire DR, Gavidia T. Contribution of Nepal's free delivery care policies in improving utilisation of maternal health services. Int J Heal Policy Manag. 2018;7(7):645-55.

24. Mehata S, Paudel YR, Dariang M, Aryal KK, Lal BK, Khanal MN, et al. Trends and Inequalities in Use of Maternal Health Care Services in Nepal: Strategy in the Search for Improvements. Biomed Res Int. 2017;2017(2008).

25. Ministry of Health, Nepal; New ERA; and ICF. 2017. Nepal Demographic and Health Survey 2016. Kathmandu, Nepal: Ministry of Health, Nepal.

26. MoHP. Inequalities in maternal health service utilization in Nepal: An analysis of routine and survey data. 2018.

27. Central Bureau of Statistics (CBS), 2020. Nepal Multiple Indicator Cluster Survey 2019, Survey Findings Report. Kathmandu, Nepal: Central Bureau of Statistics and UNICEF Nepal [Internet]. Available from: http://www.unicef.org/statistics/index_24302.html

28. Central Bureau of Statistics (CBS). Population Monograph of Nepal, Volume II (Social Demography). 2014.

29. Archer KJ, Lemeshow S. Goodness-of-fit Test for a Logistic Regression Model Fitted using Survey Sample Data. Stata J Promot Commun Stat Stata [Internet]. 2006 Feb 19;6(1):97-105. Available from:

http://journals.sagepub.com/doi/10.1177/1536867X0600600106

30. O'Donnell O, van Doorslaer E, Wagstaff A, Lindelow M. Analyzing Health Equity Using Household Survey Data [Internet]. Analyzing Health Equity Using Household Survey Data. Washington, D.C.: World Bank Group; 2007. Available from: http://documents.worldbank.org/curated/en/633931468139502235/Analyzing-health-equity-using-household-surveydata-a-guide-to-techniques-and-their-implementation

31. Jann B. Estimating Lorenz and Concentration Curves. Stata J Promot Commun Stat Stata [Internet]. 2016 Dec 1;16(4):837-66. Available from: http://journals.sagepub.com/doi/10.1177/1536867X1601600403

32. O’Donnell O, O’Neill S, Van Ourti T, Walsh B. Conindex: Estimation of Concentration Indices. Stata J Promot Commun Stat Stata [Internet]. 2016 Mar 19;16(1):112-38. Available from:

http://journals.sagepub.com/doi/10.1177/1536867X1601600112

33. Wagstaff A, Bilger M, Sajaia Z, Lokshin M. Health Equity and Financial Protection: Streamlined Analysis With ADePT Software [Internet]. Washington, DC: The World Bank; 2011. Available from:

https://openknowledge.worldbank.org/bitstream/handle/10986/2306/622580PUB0heal01476B0extop0id018459.pdf? sequence=1\&isAllowed=y

34. Dunlop CL, Benova L, Campbell O. Effect of maternal age on facility-based delivery: Analysis of first-order births in 34 countries of sub-Saharan Africa using demographic and health survey data. BMJ Open. 2018;8(4):1-9.

35. Iftikhar ul Husnain M, Rashid M, Shakoor U. Decision-making for birth location among women in Pakistan: Evidence from national survey. BMC Pregnancy Childbirth [Internet]. 2018 Jun 14 [cited 2021 May 15];18(1):1-11. Available from: https://doi.org/10.1186/s12884-018-1844-8

36. Ketemaw A, Tareke M, Dellie E, Sitotaw G, Deressa Y, Tadesse G, et al. Factors associated with institutional delivery in Ethiopia: A cross sectional study. BMC Health Serv Res. 2020;20(1):1-6.

Page $18 / 21$ 
37. Kitui J, Lewis S, Davey G. Factors influencing place of delivery for women in Kenya: An analysis of the Kenya demographic and health survey, 2008/2009. BMC Pregnancy Childbirth [Internet]. 2013 Feb 17 [cited 2021 May 11];13(1):1-10. Available from: http://www.biomedcentral.com/1471-2393/13/40

38. Say L, Raine R. A systematic review of inequalities in the use of maternal health care in developing countries: Examining the scale of the problem and the importance of context. Bull World Health Organ [Internet]. 2007 Oct [cited 2021 May 9];85(10):812-9. Available from: https://pubmed.ncbi.nlm.nih.gov/18038064/

39. Shahabuddin ASM, De Brouwere V, Adhikari R, Delamou A, Bardaj A, Delvaux T. Determinants of institutional delivery among young married women in Nepal: Evidence from the Nepal Demographic and Health Survey, 2011. BMJ Open. 2017;7(4).

40. McPherson RA, Khadka N, Moore JM, Sharma M. Are birth-preparedness programmes effective? Results from a field trial in Siraha District, Nepal. J Heal Popul Nutr [Internet]. 2006 Dec [cited 2021 May 12];24(4):479-88. Available from: /pmc/articles/PMC3001152/

41. Shabnam J, Gifford M, Dalal K. Socioeconomic inequalities in the use of delivery care services in Bangladesh: a comparative study between 2004 and 2007. Health (Irvine Calif). 2011;3(12):762-71.

42. Shah R, Rehfuess EA, Paudel D, Maskey MK, Delius M. Barriers and facilitators to institutional delivery in rural areas of Chitwan district, Nepal: A qualitative study. Reprod Health [Internet]. 2018 Jun 20 [cited 2021 May 10];15(1):1-13. Available from: https://doi.org/10.1186/s12978-018-0553-0

43. Onta S, Choulagai B, Shrestha B, Subedi N, Bhandari GP, Krettek A. Perceptions of users and providers on barriers to utilizing skilled birth care in mid- and far-western Nepal: A qualitative study. Glob Health Action [Internet]. 2014 [cited 2021 May 10];7(1):24580. Available from: https://doi.org/10.3402/gha.v7.24580

44. Khatri RB, Dangi TP, Gautam R, Shrestha KN, Homer CSE. Barriers to utilization of childbirth services of a rural birthing center in Nepal: A qualitative study. PLoS One [Internet]. 2017 May 1 [cited 2021 May 10];12(5):e0177602. Available from: https://doi.org/10.1371/journal.pone.0177602

45. Aryal KK, Dangol R, Gartoulla P, Subedi GR. Health Services Availability and Readiness in Seven Provinces of Nepal. DHS Further Analysis Reports [Internet]. 2018 [cited 2021 May 11]. Available from: http://www.newera.com.np/.

46. Acharya K, Paudel YR. General health service readiness and its association with the facility level indicators among primary health care centers and hospitals in Nepal. J Glob Heal Reports. 2019;3.

47. Dhungel S. Provincial Comparison of Development Status in Nepal: An Analysis of Human Development Trend for 1996 to 2026. J Manag Dev Stud. 2018;28:53-68.

48. Zere E, Oluwole D, Kirigia JM, Mwikisa CN, Mbeeli T. Inequities in skilled attendance at birth in Namibia: A decomposition analysis. BMC Pregnancy Childbirth [Internet]. 2011 May 14 [cited 2021 May 9];11(1):1-10. Available from: http://www.biomedcentral.com/1471-2393/11/34

49. Houweling TAJ, Ronsmans C, Campbell OMR, Kunst AE. Huge poor-rich inequalities in maternity care: An international comparative study of maternity and child care in developing countries. Bull World Health Organ [Internet]. 2007 Oct [cited 2021 May 9];85(10):745-54. Available from: https://pubmed.ncbi.nlm.nih.gov/18038055/

50. Goli S, Nawal D, Rammohan A, Sekher T V., Singh D. Decomposing the socioeconomic inequality in utilization of maternal health care services in selected countries of south Asia and sub-Saharan Africa. J Biosoc Sci [Internet]. 2018 [cited 2021 May 17];50(6):725-48. Available from: https://doi.org/10.1017/S0021932017000530

51. Obiyan MO, Kumar A. Socioeconomic Inequalities in the Use of Maternal Health Care Services in Nigeria: Trends Between 1990 and 2008. SAGE Open [Internet]. 2015 Nov 21 [cited 2021 May 9];5(4). Available from: https://us.sagepub.com/en-us/nam/open-access-at-sage

\section{Figures}


Wealth quintile

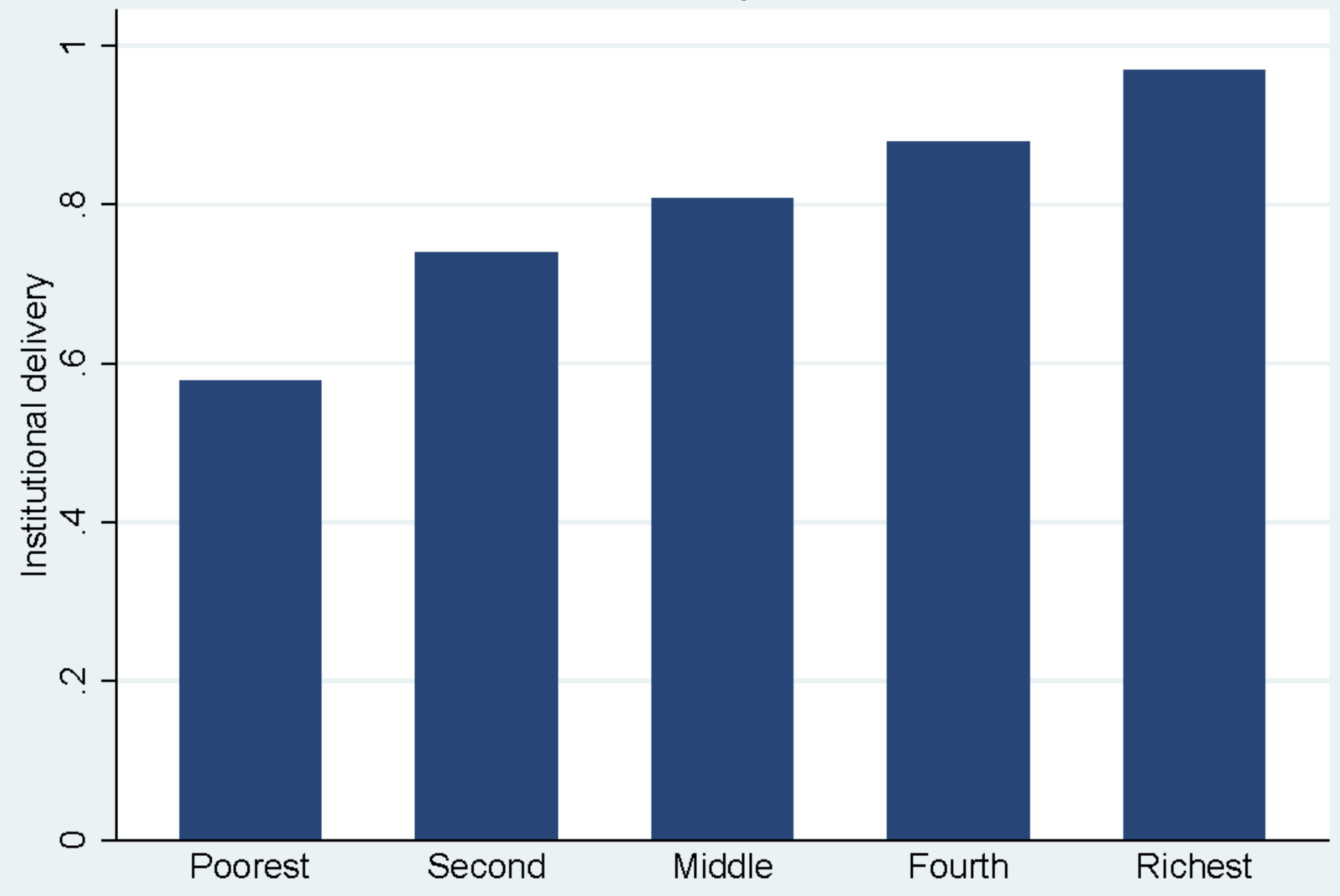

Figure 1

Institutional delivery over wealth index quintiles 


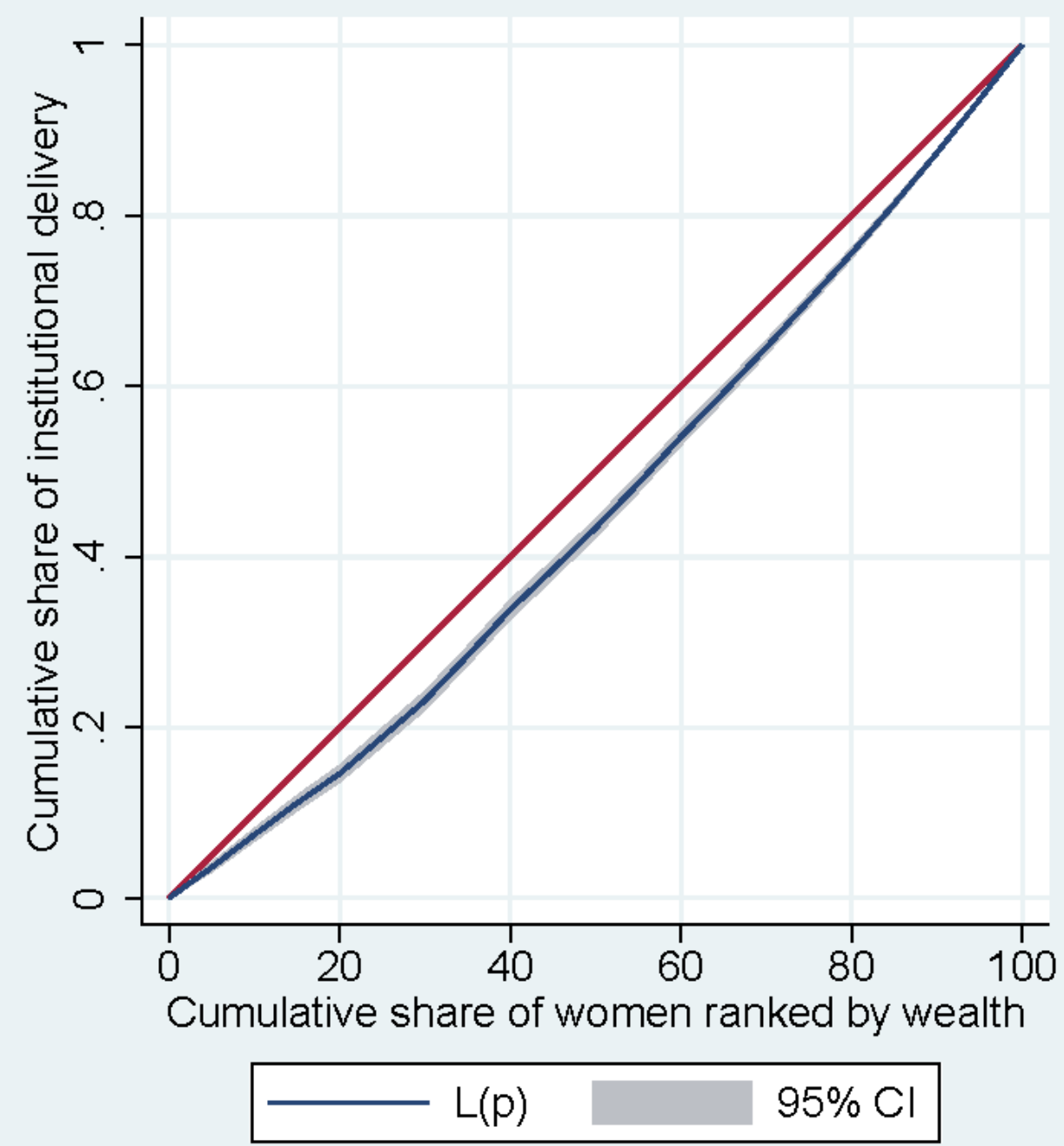

Figure 2

Concentration curve for institutional delivery against wealth rank 